\title{
Urinothorax, another complication of bladder tumor: case report
}

\author{
Saleh Abdelkerim Nedjim", El Mostapha Abdi, Hissein Hagguir, Amine Moataz, Mohamed Dakir, \\ Adil Debbagh and Rachid Aboutaieb
}

\begin{abstract}
Background: Rupture of the fornix is a rare and serious urological complication of obstructive pathologies. The main cause is ureteral stone, but rarely a bladder tumor. Described complications of fornix rupture are superinfection, perirenal abscesses and even sepsis, but not urinothorax.

Case presentation: Patient of 56 years old, active and chronic smoker, was hospitalized for anemia and obstructive renal failure on a non-documented bladder tumor; clinically, he was presented with hematuria and an intense right loin pain associated with homolateral basithoracic pain and dyspnea. The CT scan without injection showed a right perirenal collection with bilateral renal dilatation on endo-vesical tumor and a right pleural effusion of less abundance. The ratio of pleural fluid creatinine to blood creatinine was greater than 1, confirming urinothorax. As an emergency, a percutaneous nephrostomy was performed. After clinical stabilization, the patient underwent a trans-urethral resection of the bladder and derivation by a double j stent. The ultimate evolution was favorable.
\end{abstract}

Conclusions: Beyond the metabolic complications secondary to obstructions, mechanical complications, which can also be fatal, must be included.

Keywords: Bladder, Tumor, Fornix rupture, Urinothorax, Case report

\section{Background}

Rupture of the fornix is a rare urological complication of obstructive pathologies, most often secondary to an obstructive urolithiasis but rarely to be tumoral in origin. The CT scan plays an important role in the diagnosis. Emergency treatment consists of a urinary diversion. The etiological treatment depends on the cause [1]. We are reporting a first clinical case of urinothorax secondary to fornix rupture due to bladder tumor.

\section{Case presentation}

Mr. B. M, 56 years old, active and chronic smoker, without any particular pathological history, presented with an intermittent clotting total hematuria and lower urinary tract symptoms of obstructive type associated with

*Correspondence: nedjimsaleh@gmail.com

Service d'urologie/Hôpital universitaire Ibn Rochd et Faculté de Médecine et de Pharmacie, Casablanca, Maroc bilateral low back pain and a notion of non-estimated weight loss evolving over the last 4 months. Two days before his consultation at our emergency department, the symptomatology was aggravated by the accentuation of hematuria and the installation of an intense lower back pain and right side basal chest pain without dyspnea. The clinical examination revealed a patient in a fairly good general condition, hemodynamically stable with bilateral lumbar sensitivity more dominant on the right without a full bladder. The external genitalia were normal and the per rectal examination concluded an infiltrated right side of the bladder, absence of lower limbs oedem. Biologically, hemoglobin was $8.6 \mathrm{~g} / \mathrm{dl}$, hyperleukocytosis at $4,000 / \mathrm{mm} 3$ with neutrophilic nuclear predominance and plasma creatinine $82 \mathrm{mg} / \mathrm{l}$ with kalemia $4.4 \mathrm{mEq} / \mathrm{l}$. an abdomino-pelvic ultrasound showed a bilateral ureteropyelocalicielle dilatation (moderate on the left side and major on the right side) with a heterogeneous intravesical tumor. Chest X-ray was requested and showed a left 
pleural effusion. A CT scan without injection of iodinated contrast confirmed the presence of a right perirenal collection with bilateral ureterohydronephrosis (Fig. 1) on a heterogeneous intravesical tumor (Fig. 2) and a right sided pleural effusion of a small amount (Fig. 3).

The emergency management plan started by bladder catheterization and declotting, an intravenous access for rehydration and antibiotic therapy, transfusion and bilateral percutaneous nephrostomy. After pneumological evaluation, a pleural puncture for diagnostic purposes (biochemical, bacteriological and cytological study) was performed. After clinical stabilization, a transurethral bladder tumor resection was performed with bilateral double J-tube stent. The histopathological study of the resection cuts confirmed a high-grade urothelial bladder carcinoma infiltrating the lamina propria.

\section{Discussion}

To our knowledge, this is the first reported clinical case of urinothorax secondary to fornix rupture due to bladder tumor. Based on the various data in the literature, we will discuss our case.

Spontaneous fornix rupture is a rare urological emergency and is one of the possible complications of excretory tract obstructions [1]. Obstruction of the upper urinary tract causes pressure in the renal pelvis that would lead to possible rupture of the fornix [2]. In most cases, it manifests itself by the sudden appearance of an intense loin pain. Diagnosis can be made by CT scan [3]. Total clotting gross hematuria associated with acute low back pain was the clinical manifestation in our patient. Chest pain was present.

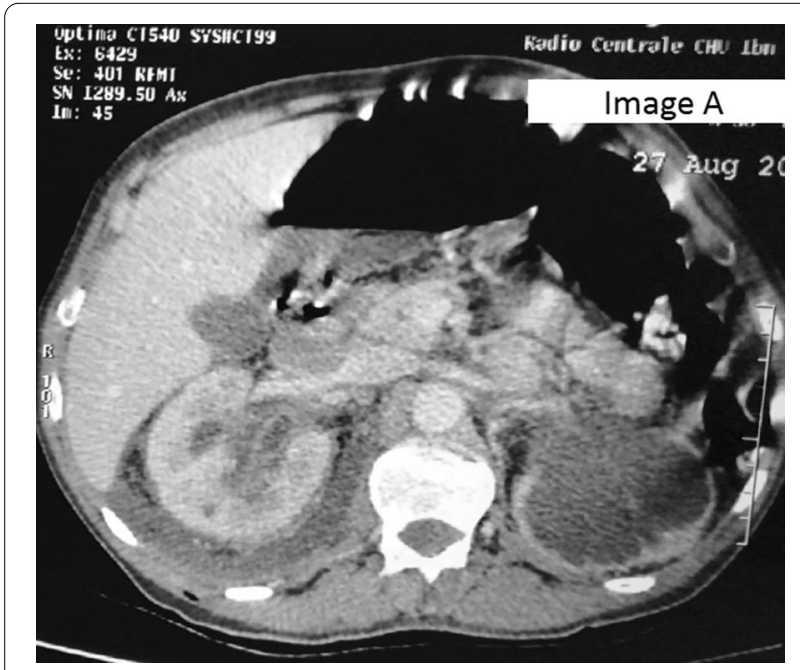

Fig. 1 Right perirenal effusion

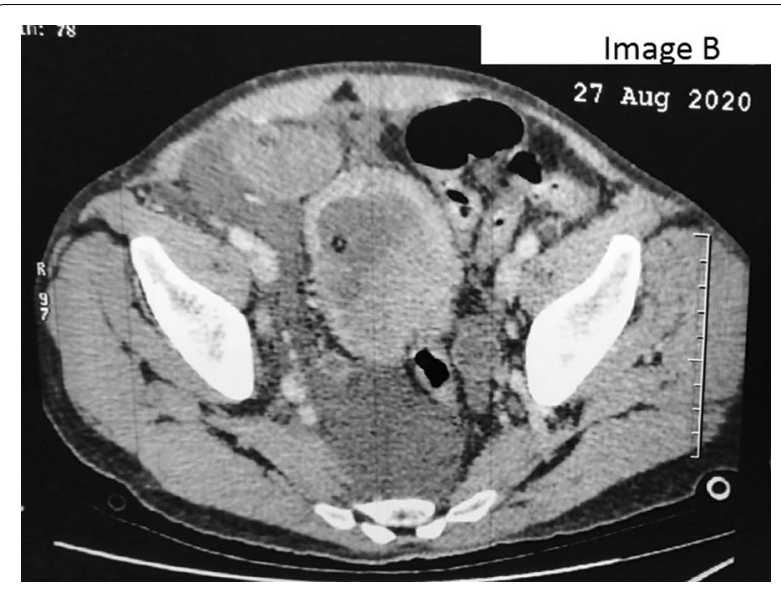

Fig. 2 Heterogeneous intravesical process

It is a predominantly male entity ( $70 \%$ of men) that can lead to acute renal failure in $30 \%$ of cases. Urine culture was positive in 6 patients (15\%) [4]. In this study, the patient was 56 years old. A renal insufficiency was found, the bacteriological examination of the urine isolated a germ, a multi-sensitive Escherichia Coli.

Out of 162 patients, urolithiasis was found in $60 \%$ of cases as the cause and in $28 \%$ of cases no cause was found for fornix rupture. Other causes were isolated but not the bladder tumor [1]. Urinothorax is a rare complication of blunt kidney trauma, ureteral instrumentation or ureteral surgery. Leakage from the urinary tract causes a urinoma (retroperitoneal accumulation of fluid) which can lead to a urinothorax [5]. The most specific biochemical aspect of urinothorax is the presence of a ratio of pleural fluid creatinine to blood creatinine greater than 1 [6]. The management of urinothorax requires a multidisciplinary

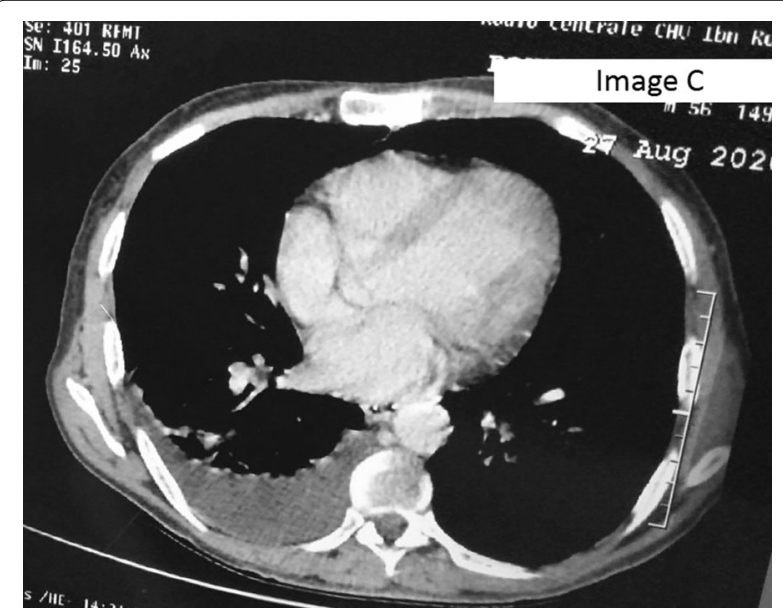

Fig. 3 Right pleural effusion of low abundance 
approach based on the correction of the underlying genitourinary obstructive pathology, which allows for a rapid and spontaneous resolution of the pleural effusion [7]. We are reporting a case of ruptured fornix due to bladder tumor leading to an urinothorax. The biochemical analysis allowed us to consolidate the diagnosis.

Conservative management is a valid option in uncomplicated cases. Urinary derivation should be reserved for complicated cases or cases with significant urinoma [4]. Specifically, the emergency treatment consisted of a bilateral nephrostomy, urinary diversion which has a double interest in this patient (urinoma and obstructive renal failure). The definitive treatment consisted of endoscopic resection of the tumor with bilateral double J-tube stenting. Since our patient was asymptomatic on the respiratory level and the effusion was of low abundance, the urinothorax was respected. On the time of control by chest X-ray, we did not notice any pleural effusion. The consequences were simple by the improvement of clinical signs and symptoms and the normalization of biological parameters.

\section{Conclusions}

Although rare or even unknown, the authors draw attention to the possibility of a urinothorax which may be due to a rupture of fornix in front of any obstructive pathology of the excretory tract. Beyond the metabolic complications secondary to obstructions, mechanical complications, which can also be fatal, must be included.

\section{Abbreviations}

g/dl: Gram per deciliter; /mm3: Per millicubic meter; mEq/l: Milliequivalent per liter.

\section{Acknowledgements}

Not applicable.

\section{Authors' contributions}

NAS and AEM contributed to conception, bibliographical research and writing, NAS and $\mathrm{HH}$ contributed to reading and translation; MA, DM, DA and AR served as trainer and corrector. All authors have read and approved the manuscript.
Funding

Not applicable.

Availability of data and material

Data and materials are available. If needed, they can be provided to the publisher.

\section{Declarations}

Ethics approval and consent to participate

Not applicable.

\section{Consent for publication}

We have obtained written and signed consent from the patient for publication.

\section{Competing interest}

The authors declare that they have no competing interests.

Received: 7 January 2021 Accepted: 9 Auqust 2021

Published online: 06 September 2021

References

1. Doehn C, Fiola L, Peter M, Jocham D (2010) Ursachen und Verlauf bei Fornixruptur. Aktuelle Urologie - AKTUEL UROL 41:119-121. https://doi. org/10.1055/s-0030-1247252

2. Tanwar S, Joshi A (2011) A blow-out. Am J Med 124(1):37-39

3. Coelho RF, Schneider-Monteiro ED, Mesquita JL, Mazzucchi E, Marmo Lucon A, Srougi M (2007) Renal and perinephric abscesses: analysis of 65 consecutive cases. World J Surg 31:431-436

4. Al-mujalhem AG, Aziz MS, Sultan MF, Al-maghraby AM, Al-shazly MA (2017) Spontaneous forniceal rupture: Can it be treated conservatively? Urol Ann 9:41-44

5. Oguzulgen I, Oğuzülgen A, Sinik Z, Köktürk O, Ekim N, Karaoğlan U (2002) An unusual cause of urinothorax. Respir Int Rev Thorac Dis 69:273-274. https://doi.org/10.1159/000063633

6. Garcia-Pachon E, Padilla-Navas I (2004) Urinothorax: case report and review of the literature with emphasis on biochemical diagnosis. Respiration 71:533-536

7. Salcedo JR (1986) Urinothorax: report of 4 cases and review of the literature. J Urol 135(4):805-808

\section{Publisher's note}

Springer Nature remains neutral with regard to jurisdictional claims in published maps and institutional affiliations.

\section{Submit your manuscript to a SpringerOpen ${ }^{\circ}$ journal and benefit from:}

- Convenient online submission

- Rigorous peer review

- Open access: articles freely available online

- High visibility within the field

- Retaining the copyright to your article

Submit your next manuscript at springeropen.com 